УДК 550.348 .435

\title{
ОЧАГОВЫЕ ПАРАМЕТРЫ
}

\section{ЗЕМЛЕТРЯСЕНИЙ КРЫМСКО-ЧЕРНОМОРСКОГО РЕГИОНА в 20152.}

\author{
Б.Г. Пустовитенко ${ }^{1}$, Э.Э. Эреджепов ${ }^{1,2}$
}

\begin{abstract}
${ }^{1}$ ГАУ «Крымский Республиканский Центр оценки сейсмической и оползневой опасности, технического обследования объектов строительства»

${ }^{2}$ Институт сейсмологии и геодинамики ФГАОУВО «Крымский федеральный университет имени B.И. Вернадского», г.Симферополь, seismosilver1@mail.ru,bpustovitenko@mail.ru
\end{abstract}

\begin{abstract}
Аннотация. Приведены результаты определения спектральных и динамических параметров очагов 16 землетрясений Крыма 2015 г. в диапазоне энергетических классов $K_{\Pi}=6.5-10.8$ по амплитудным спектрам объемных $P$ - и $S$-волн, зарегистрированных сетью региональных сейсмических станций Крыма. Наибольшие значения динамических параметров $\left(M_{0}, r_{0}, \Delta \sigma, \varepsilon, \eta \sigma, \overline{\mathrm{u}}, E_{\mathrm{U}}\right.$ и $\left.M w\right)$ установлены для землетрясений 13 июня и 16 августа с $K_{\Pi}=10.8$ и $M w=3.6$ и 3.8 соответственно, произошедших в Азово-Кубанской и Керченско-Анапской областях. Для землетрясения 16 августа получено решение механизма очага и определена направленность излучения на станции регистрации для учета при расчете скалярного сейсмического момента. Землетрясение произошло под действием горизонтальных сил растяжения. Подвижка по обеим нодальным плоскостям - косой сброс. Средние значения сейсмических моментов и радиусов круговой дислокации за 2015 г. в пределах погрешностей их определения удовлетворяют долговременным зависимостям параметров от энергетического уровня землетрясений, полученным по аналоговым записям. Дается анализ полученных результатов.
\end{abstract}

Ключевые слова: механизм очага, амплитудный спектр, модель Бруна, сейсмический момент, радиус дислокации, сброшенное и кажущееся напряжения, подвижка по разрыву, радиационное трение.

DOI: $10.35540 / 1818-6254.2021 .24 .22$

Для цитирования: Пустовитенко Б.Г., Эреджепов Э.Э. Очаговые параметры землетрясений Крымско-Черноморского региона в 2015 г. // Землетрясения Северной Евразии. - 2021. Вып. 24 (2015 г.). - С. 226-236. doi: 10.35540/1818-6254.2021.24.22

Введение. Современные алгоритмы и методы обработки сейсмических колебаний позволяют определять основные параметры практически всех зарегистрированных сейсмических событий. В то же время с определением дополнительных очаговых параметров дело обстоит гораздо сложнее. Это связано с жесткими условиями отбора волновых форм для анализа, необходимостью знания строения среды на пути распространения сейсмических волн, учета амплитудно-частотных характеристик сейсмографов и др. В связи с этим восстановление динамических параметров очагов не входит в обязательный регламент работ в центрах обработки данных и является научно-методической и исследовательской задачей. Крым относится к тем немногочисленным регионам, где определение и публикация динамических параметров очагов местных землетрясений по записям региональных сейсмических станций стали ежегодными.

Исходные данные. Для восстановления очаговых параметров землетрясений КрымскоЧерноморского региона 2015 г. выбраны все наиболее значимые представительные сейсмические события с $K_{\Pi}>9.0$, а также более слабые толчки недостаточно изученной Судакско-Феодосийской зоны (район № 4). Пространственное расположение эпицентров 16 землетрясений с энергетическими классами $K_{\Pi}=6.5-10.8$, для которых определены очаговые параметры, даны на рисунке 1, а их основные параметры по данным обработки в Крыму [1] приведены в таблице 1.

Наибольшее количество изученных землетрясений (пять событий) относится к СудакскоФеодосийской зоне региона (район № 4), четыре - к Алуштинской (район № 3), по три - к АзовоКубанской и Керченско-Анапской зонам очагов (районы № 7 и № 5), одно - к Черноморской впадине (район № 9).

Таблица 1. Основные параметры землетрясений Крымско-Черноморского региона за 2015 г., для которых определены очаговые параметры

\begin{tabular}{|c|c|c|c|c|c|c|c|c|c|c|}
\hline \multirow{2}{*}{ № } & \multirow{2}{*}{ Район } & \multirow{2}{*}{$\begin{array}{l}\text { Дата, } \\
\partial \quad м\end{array}$} & \multirow{2}{*}{$\begin{array}{c}t_{0} \\
\varphi \quad \text { мин с }\end{array}$} & \multicolumn{2}{|c|}{ Эпицентр } & \multirow{2}{*}{$\begin{array}{c}h, \\
\kappa M\end{array}$} & \multicolumn{3}{|c|}{ Магнитуда } & \multirow{2}{*}{$K_{\Pi}$} \\
\hline & & & & $\varphi^{\circ}, \mathrm{N}$ & $\lambda^{\circ}, \mathrm{E}$ & & $M c$ & $M w / n$ & $M L_{\text {wsg }} / n$ & \\
\hline 1 & 2 & 3 & 4 & 5 & 6 & 7 & 8 & 9 & 10 & 11 \\
\hline 1 & Судакско-Феодосийский (№ 4) & 04.01 & 144306.5 & 44.85 & 35.05 & 25 & - & $2.2 / 4$ & - & 6.5 \\
\hline
\end{tabular}




\begin{tabular}{|c|c|c|c|c|c|c|c|c|c|c|}
\hline \multirow[b]{2}{*}{ № } & \multirow{2}{*}{ Район } & \multirow{2}{*}{$\begin{array}{l}\text { Дата, } \\
\partial \quad \mu\end{array}$} & \multirow{2}{*}{$\begin{array}{cc} & t_{0}, \\
\varphi \quad \text { мин } \quad \text { c }\end{array}$} & \multicolumn{2}{|c|}{ Эпицентр } & $h$, & \multicolumn{3}{|c|}{ Магнитуда } & \multirow{2}{*}{$K_{\Pi}$} \\
\hline & & & & $\varphi^{\circ}, \mathrm{N}$ & $\lambda^{\circ}, \mathrm{E}$ & KM & $M c$ & $M w / n$, & $M L_{\text {wsg }} / n$ & \\
\hline 2 & Азово-Кубанский (№ 7) & 17.03 & 065458.0 & 45.73 & 35.82 & 17 & - & $3.0 / 4$ & - & 8.7 \\
\hline 3 & Керченско-Анапский (№ 5) & 18.03 & 094725.1 & 45.34 & 37.63 & 35 & 2.7 & $3.3 / 4$ & $3.0 / 4$ & 9.3 \\
\hline 4 & Судакско-Феодосийский(№ 4) & 09.04 & 184712.7 & 44.49 & 35.72 & 12 & - & $2.7 / 3$ & - & 7.7 \\
\hline 5 & Судакско-Феодосийский (№ 4) & 04.05 & 161954.4 & 44.43 & 35.84 & 12 & - & $2.5 / 2$ & - & 7.3 \\
\hline 6 & Черноморская впадина (№ 9) & 21.05 & 205234.8 & 43.38 & 35.01 & 7 & - & $3.1 / 6$ & - & 9.0 \\
\hline 7 & Азово-Кубанский (№ 7) & 13.06 & 115414.8 & 46.47 & 35.16 & 11 & - & $3.6 / 7$ & $3.7 / 7$ & 10.8 \\
\hline 8 & Керченско-Анапский (№5) & 29.06 & 024737.4 & 44.78 & 36.24 & 14 & - & $2.9 / 4$ & - & 8.7 \\
\hline 9 & Азово-Кубанский (№ 7) & 05.07 & 132334.1 & 45.74 & 36.69 & 18 & 3.1 & $3.5 / 8$ & $3.4 / 5$ & 9.9 \\
\hline 10 & Керченско-Анапский (№ 5) & 16.08 & 22380.2 & 44.56 & 37.39 & 7 & - & $3.8 / 6$ & $3.8 / 6$ & 10.8 \\
\hline 11 & Алуштинский (№ 3) & 29.08 & 045349.7 & 44.51 & 34.42 & 20 & 2.5 & $3.3 / 6$ & $3.0 / 5$ & 9.5 \\
\hline 12 & Алуштинский (№ 3) & 29.08 & 050212.3 & 44.52 & 34.41 & 21 & 2.3 & $3.1 / 3$ & $2.7 / 5$ & 9.0 \\
\hline 13 & Алуштинский (№ 3) & 30.08 & 025148.1 & 44.46 & 34.47 & 18 & - & $2.6 / 4$ & - & 7.7 \\
\hline 14 & Судакско-Феодосийский (№ 4) & 30.08 & 104724.1 & 44.60 & 35.4 & 11 & 2.4 & $3.1 / 7$ & $2.9 / 6$ & 9.3 \\
\hline 15 & Судакско-Феодосийский (№ 4) & 30.08 & 234444.6 & 44.67 & 35.24 & 27 & - & $2.6 / 2$ & - & 7.3 \\
\hline 16 & Алуштинский (№ 3) & 23.09 & 025304.2 & 44.53 & 34.59 & 35 & 2.7 & $3.1 / 5$ & $2.7 / 6$ & 9.0 \\
\hline
\end{tabular}

Примечание. Параметры землетрясений в графах 2-7, 9-11 соответствуют таковым в [1]; значения $M w / n-$ из табл. 4; $n$ - число индивидуальных определений, участвовавших в осреднении.

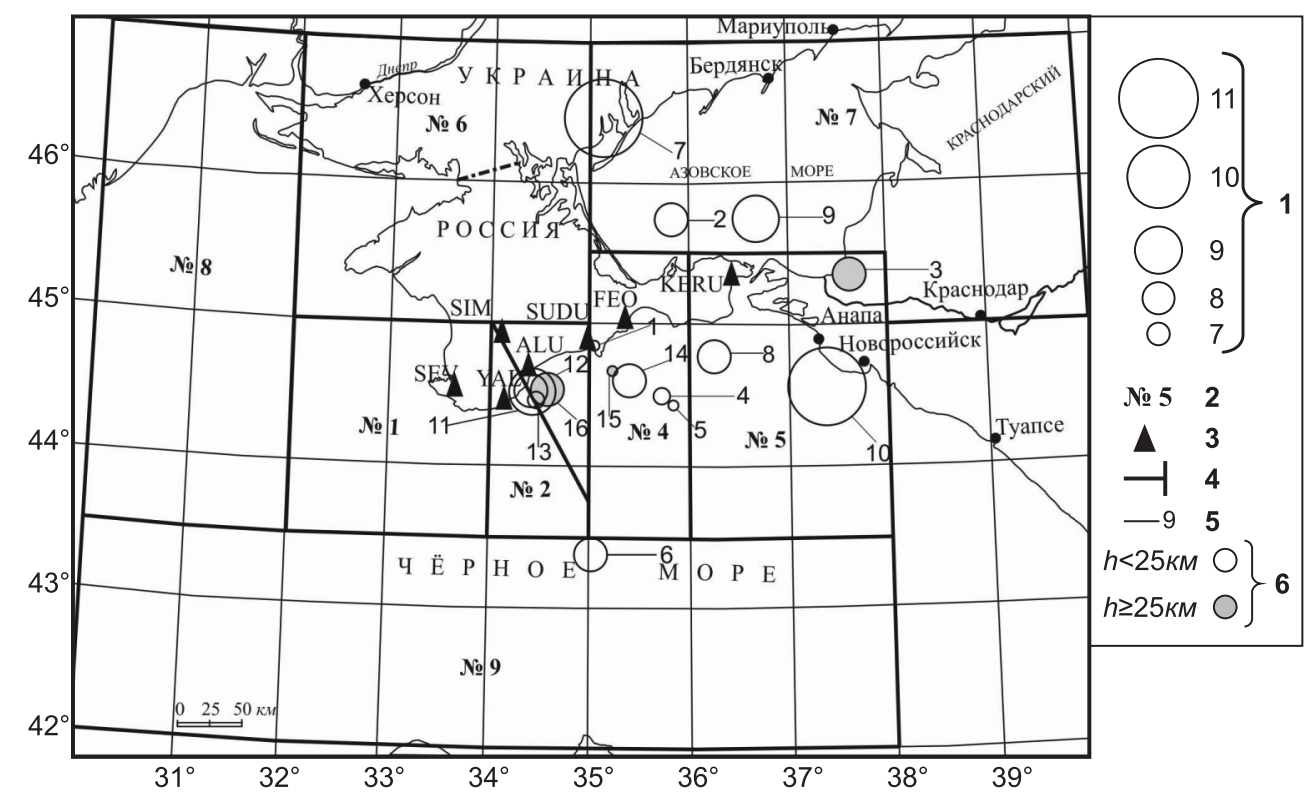

Puc. 1. Карта эпицентров землетрясений Крымско-Черноморского региона 2015 г., для которых восстановлены очаговые параметры

1 - энергетический класс $K_{\Pi}$ [2]; 2 - номер района; 3 - сейсмическая станция; 4 - граница района; 5 -номер землетрясения по табл. $1 ; 6$ - глубина очага $h, \kappa M$.

Для расчета амплитудных спектров и восстановления по ним динамических параметров очагов использовано 28 четких записей продольных $(P)$ и 91 - поперечных $(S)$ волн на сейсмических станциях: «Алушта» (ALU), «Севастополь» (SEV), «Симферополь» (SIM), «Судак» (SUDU), для которых в 2015 г. была проведена калибровка сейсмографов и надежно рассчитаны амплитудно-частотные и фазовые характеристики.

Наибольшее количество спектров получено по записям сейсмических станций «Судак» и «Севастополь». Процент участия этих же станций в общей оценке динамических параметров отдельных землетрясений также наибольший, соответственно $100 \%$ и $75 \%$. Меньше всего для анализа привлекались записи станции «Симферополь» (44 \%), особенно для относительно слабых землетрясений, при которых сейсмические колебания часто осложнены высоким уровнем городских микросейсмических шумов. Большая часть динамических параметров очагов землетрясений восстановлена по характеристикам амплитудных спектров поперечных волн $(S)$, амплитуды которых почти всегда в несколько раз превышают амплитуды продольных волн $(P)$.

Для наиболее сильного землетрясения 16 августа получено решение механизма очага. 
Механизм очага землетрясения 16 августа (табл. 2) восстановлен с использованием волновых форм по записям станций, окружающих очаг в широком азимутальном створе, что в совокупности со знаками первых вступлений, опубликованных в Международном сейсмологическом центре [3], позволило получить надежное решение механизма очага [4].

Определение двух возможных положений поверхности разрыва и осей главных напряжений, действующих в очаге, проведено по стандартной методике [5]. Углы выхода сейсмических волн определены для удаленных станций по годографу «ak135» [6], а для близких - по региональному годографу [7].

Таблица 2. Параметры механизма очага землетрясения 16 августа 2015 г. в $22^{\mathrm{h}} 38^{\mathrm{m}}$ с $K_{\Pi}=10.8$

\begin{tabular}{|c|c|c|c|c|c|c|c|c|c|c|c|}
\hline \multirow{2}{*}{$\begin{array}{l}\text { Дата, } \\
\partial \quad \text { M }\end{array}$} & \multirow[b]{2}{*}{$\begin{array}{c}t_{0}, \\
\text { ч мин с }\end{array}$} & \multirow{2}{*}{$\begin{array}{c}h, \\
\kappa M\end{array}$} & \multirow{2}{*}{\begin{tabular}{|l|l|} 
Магнитуды \\
$M w$ & $m_{\mathrm{b}}(M S H)$ \\
\end{tabular}} & \multirow[b]{2}{*}{$K_{\Pi}$} & \multicolumn{4}{|c|}{ Оси главных напряжений } & \multicolumn{2}{|c|}{ Нодальные плоскости } & \multirow[b]{2}{*}{ Источник } \\
\hline & & & & & \begin{tabular}{l|l} 
& $T$ \\
$P I$ & $A Z M$
\end{tabular} & & $N$ & $P$ & $N P 1$ & $N P 2$ & \\
\hline 16.08 & 22380.2 & 7 & \begin{tabular}{|l|l|}
3.8 & $3.7(3.8)$ \\
\end{tabular} & 10.8 & \begin{tabular}{l|l}
0 & 252
\end{tabular} & 6 & 342 & \begin{tabular}{|l|l|}
84 & 162 \\
\end{tabular} & \begin{tabular}{|l|l|l|}
167 & 45 & -82 \\
\end{tabular} & \begin{tabular}{|l|l|l|}
336 & 45 & -98 \\
\end{tabular} & [4] \\
\hline
\end{tabular}

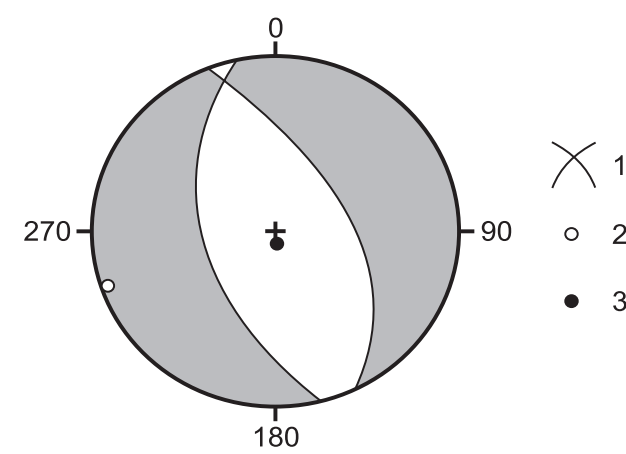

Puc. 2. Диаграмма механизма очага землетрясения 16 августа 2015 г. в проекции нижней полусферы

1 - нодальные линии; 2, 3 - оси главных напряжений растяжения и сжатия соответственно; зачернена область волн сжатия.
В соответствии с полученным решением (табл. 2, рис. 2), землетрясение произошло под действием горизонтальных $\left(P L_{\mathrm{P}}=0^{\circ}\right)$ сил растяжения, ориентированных близширотно $\left(A Z M_{\mathrm{P}}=252^{\circ}\right)$. Подвижка по обеим нодальным плоскостям - косой сброс, с незначительной компонентой сдвига, которой можно пренебречь (рис. 2). Обе нодальные плоскости - наклонные $\left(D P=45^{\circ}\right)$ субмеридионального $\left(S T K_{\mathrm{NP} 1}=167^{\circ}\right)$ и субдиагонального простирания $\left(S T K_{\mathrm{NP} 2}=336^{\circ}\right)$.

По данным о параметрах полученного механизма очага определена направленность излучения волн $P$ и $S$ для каждой станции (табл. 3) для учета при определении скалярного сейсмического момента.

Tаблица 3. Значения $R_{\theta \varphi}$ для землетрясения 16 августа 2015 г.

\begin{tabular}{c|c|c|c|c|c|c}
\hline Станция & \multicolumn{2}{|c|}{ ALU } & SIM & SEV & \multicolumn{2}{c}{ SUDU } \\
\hline Тип волны & $P$ & $S$ & $S$ & $S$ & $P$ & $S$ \\
\hline$R_{\theta \varphi}$ & 0.16 & 0.70 & 0.71 & 0.70 & 0.18 & 0.69 \\
\hline
\end{tabular}

Методика обработки и интерпретация амплитудных спектров. Для анализа отобраны записи только с четкими фазами объемных $P$ - и $S$-волн, не осложненные микросейсмическим шумом, с превышением полезного сигнала над фоном помех в два и более раз. Пример такой записи дан на рисунке 3.

Амплитудный спектр поперечных волн $(S)$ во всех случаях рассчитывался по двум горизонтальным составляющим записи $(\mathrm{N}-\mathrm{S})$ и $(\mathrm{E}-\mathrm{W})$, затем вычислялся полный вектор колебаний. Для продольных волн $(P)$ спектр определялся по вертикальной составляющей $(\mathrm{Z})$. Относительная длительность $\tau$ исследуемого участка записи принята равной интервалу времени от момента вступления $S$ - и $P$-волн до времени спада их максимальных амплитуд $A_{\max }$ на уровень ${ }^{1} / 3 A_{\max }$ [8].

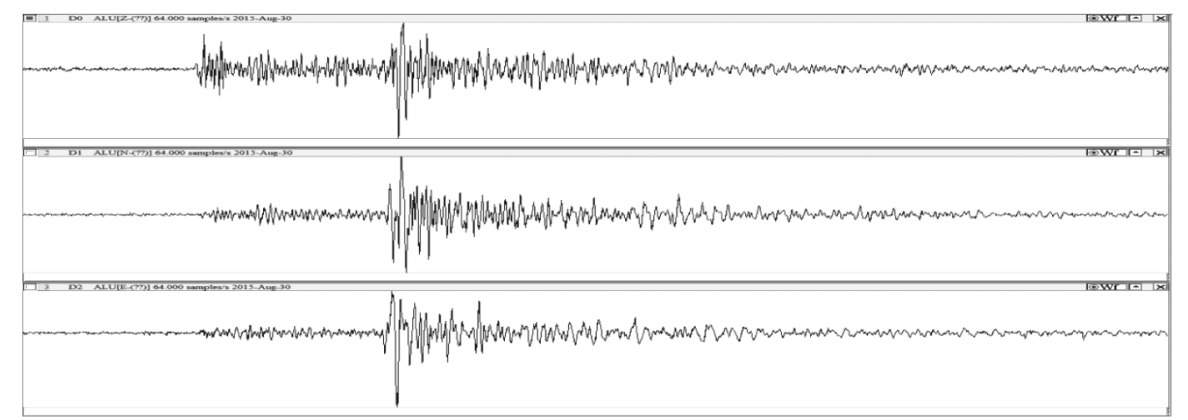

Puc. 3. Пример записи землетрясения 30 августа с $K_{П}=9.3$ (№ 14 по таблице 1) на станции «Судак» ( $\Delta=45 \mathrm{kм}$ ) по составляющим Z, N-S, E-W (сверху вниз) 
Для интерпретации спектров использована теоретическая дислокационная модель Бруна $\left(\omega^{-2}\right)$ [9], согласно которой амплитудный спектр объемной волны характеризуется тремя основными параметрами: спектральной плотностью $\Omega_{0}(x, f)$ в длиннопериодной части (при $f \rightarrow 0$ ), угловой частотой $f_{0}\left(\omega_{0}\right)$ и углом наклона $\gamma \sim-2$.

Полученные амплитудные спектры записей землетрясений Крыма за 2015 г. уверенно аппроксимируются в рамках выбранной теоретической модели (рис. 4).

Ввиду многочисленности рассчитанных спектров, их все невозможно представить в данной статье в полном объеме, поэтому на рисунке 4 приведены только характерные примеры для землетрясений по разным типам волн и отдельным станциям регистрации.

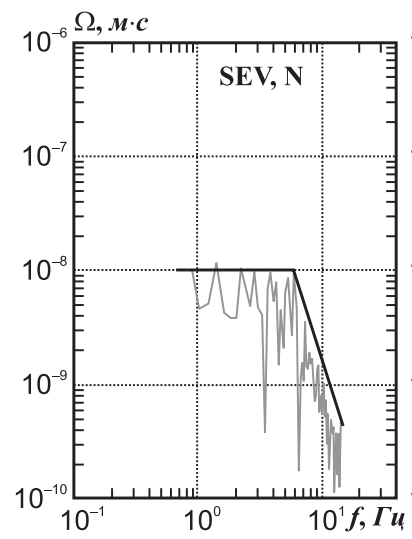

17 марта в $06^{\mathrm{h}} 43^{\mathrm{m}} 6.5^{\mathrm{s}}$ (№ 2)

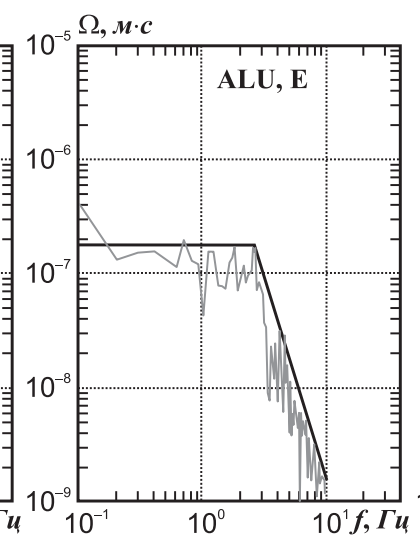

21 мая, в $20^{\mathrm{h}} 52^{\mathrm{m}} 34.8^{\mathrm{s}}$

(№ 6)

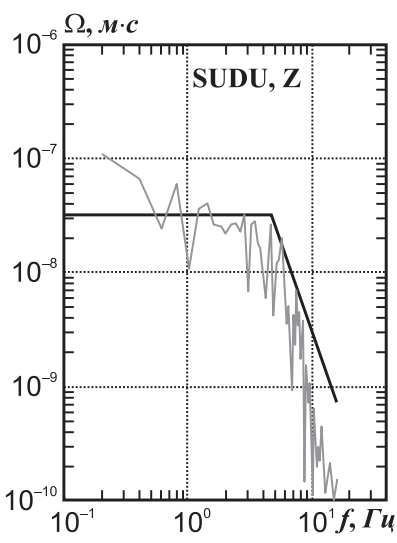

5 июля, в $13^{\mathrm{h}} 23^{\mathrm{m}} 34.1^{\mathrm{s}}$ (№ 9)

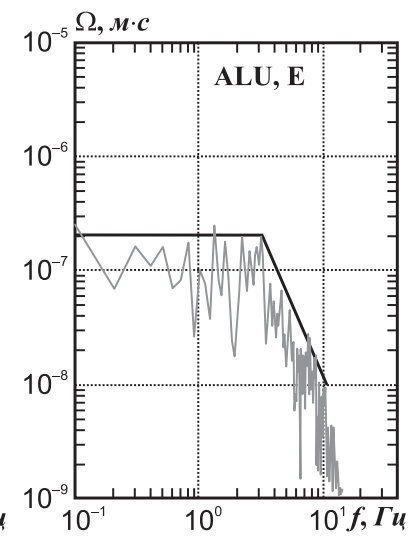

23 сентября в $02^{\mathrm{h}} 53^{\mathrm{m}} 4.2^{\mathrm{s}}$ (№ 16)

Puc. 4. Примеры амплитудных спектров объемных сейсмических волн землетрясений Крыма за 2015 г. по записям региональных цифровых сейсмостанций и их аппроксимация в рамках теоретической модели Бруна. Номера и даты землетрясений соответствуют таковым в табл. 1

Расчет динамических параметров очагов выполнен в рамках дислокационной модели Бруна [9]. Использованы две главные характеристики амплитудных спектров: спектральная плотность $\Omega_{0}$, которая пропорциональна скалярному сейсмическому моменту $M_{0}(1)$, и угловая частота $f_{0}$, прямо связанная с размером дислокации $r_{0}(2)$ :

$$
M_{0}=\Omega_{0}\left(4 \pi \rho \cdot V^{3}\right) / R_{\theta \varphi} \cdot G(\Delta, h) \cdot C(\omega) \cdot \operatorname{Sm}(f),
$$

где $\Omega_{0}$ - максимальное значение спектральной плотности при $\omega \rightarrow 0 ; V$ - скорость распространения объемной волны; $\rho$ - плотность пород в окрестности очага; $R_{\theta \varphi}-$ направленность излучения из очага на станцию регистрации; $G(\Delta, h)$ - поправка за геометрическое расхождение; $C(\omega)$ частотная характеристика среды под станцией; $S m(f)$ - поправка за неупругое затухание в мантии.

Методика учета всех этих факторов при переходе от станционного спектра к спектру источника подробно изложена в работах [8-10] и не изменилась по сравнению с предыдущими годами.

Для дислокационной модели Бруна с разрывом в виде круга, радиус дислокации $r_{0}$ вычисляется по угловой частоте $f_{0}$ по формуле:

$$
r_{0}=2.34 \frac{V}{2 \pi f_{0}} .
$$

По найденным значениям сейсмического момента $M_{0}$ и размеров разрыва $r_{0}$ определены средние величины напряжений в очаге (сброшенное $\Delta \sigma$ и кажущееся $\eta \sigma)$ и средняя подвижка по разрыву $U$ по формулам (3-5) из работ $[11,12]$ :

$$
\Delta \sigma=\frac{7 M_{0}}{16 r_{0}^{3}}(3), \eta \sigma=\frac{\mu \cdot E_{\mathrm{S}}}{M_{0}}(4), U=\frac{M_{0}}{\mu \cdot \pi r_{0}^{2}}
$$

где $\mu$ - модуль сдвига; $\eta$ - сейсмический коэффициент полезного действия; $E_{\mathrm{S}}-$ энергия источника $\left(\lg E_{\mathrm{S}}=11.8+1.5 M_{\mathrm{LH}}\right)$. 
Величина радиационного трения $\Delta \sigma_{r}$, связанного с шероховатостью поверхности разрыва в очаге, определяется по формуле (6) из [11]:

$$
\Delta \sigma_{\mathrm{r}}=1 / 2 \Delta \sigma-\eta \sigma .
$$

Оценка энергии $E_{\mathrm{U}}$ выполнена по дислокации в очаге и сброшенному напряжению [9]:

$$
E_{\mathrm{U}}=\frac{1}{2} \Delta \sigma U \cdot \pi r_{0}^{2}
$$

С использованием уравнения из теории упругости, связывающего деформацию с напряжением, оценена упругая деформация сдвига в окрестности очага:

$$
\varepsilon=\frac{\Delta \sigma}{\mu}
$$

Моментная магнитуда рассчитана по индивидуальным оценкам сейсмических моментов $M_{0}$ с использованием формулы Канамори [13]:

$$
M w=2 / 3 \cdot\left(\lg M_{0}+7\right)-10.7
$$

где $M_{0}$ имеет размерность $H \cdot M$.

Вычисление средних значений параметров $S$ и стандартных отклонений $\delta S$ для конкретного землетрясения выполнено по станционным определениям с учетом логнормального закона распределения величин [8]. Станционные параметры радиационного трения $\Delta \sigma_{\mathrm{r}}$ получились отрицательными или знакопеременными, в связи с этим их среднее значение вычислено по среднегеометрическим для данного очага напряжениям $\Delta \sigma$ и $\eta \sigma$ по формуле (6). В этом случае графа «стандартное отклонение» в таблице 4 не заполнялась. Средняя величина моментной магнитуды $M w$ определена как среднее арифметическое с соответствующей погрешностью.

Большинство динамических параметров получено по группе независимых станционных определений. Только для двух слабых сейсмических толчков (№ 5 и № 15) с энергетическим классом $K_{\Pi}=7.3$, произошедших в Судакско-Феодосийской зоне, динамические параметры рассчитаны по записям $P$ - и $S$-волн на ближайшей к очагу станции «Судак».

Результаты расчета станционных и средних для землетрясения спектральных и динамических параметров представлены в таблице 4. Для каждой станции указаны эпицентральное рассто-

\begin{tabular}{|c|c|c|c|c|c|c|c|c|c|c|c|c|c|c|c|}
\hline $\begin{array}{l}\text { Код } \\
\text { ст. }\end{array}$ & Волна & Сост & $\begin{array}{c}\Delta, \\
\kappa M\end{array}$ & $\begin{array}{c}\Omega_{0} \cdot 10^{-6} \\
M^{\prime} \cdot C\end{array}$ & $\begin{array}{c}\Sigma \Omega_{0} \cdot 10^{-6}, \\
{ }^{\prime} \cdot \mathcal{C}\end{array}$ & $\begin{array}{l}f_{0}, \\
\Gamma u\end{array}$ & $\begin{array}{c}M_{0} \cdot 10^{13} \\
H \cdot M\end{array}$ & $\begin{array}{l}r_{0} \\
\kappa M\end{array}$ & $\begin{array}{c}\Delta \sigma \cdot 10^{5}, \\
П a\end{array}$ & $\varepsilon \cdot 10^{-6}$ & $\begin{array}{c}\bar{u} \cdot 10^{-2} \\
\mathcal{M}\end{array}$ & $\begin{array}{c}\sigma \cdot 10^{3} \\
\Pi a\end{array}$ & $\begin{array}{l}\Delta \sigma_{\mathrm{r}} \cdot 10^{3}, \\
\Pi a\end{array}$ & $\begin{array}{c}E_{\mathrm{u}} \cdot 10^{8}, \\
\text { Дж, }\end{array}$ & $M w$ \\
\hline 1 & 2 & 3 & 4 & 5 & 6 & 7 & 8 & 9 & 10 & 11 & 12 & 13 & 14 & 15 & 16 \\
\hline \multicolumn{16}{|c|}{ Землетрясение (№ 1) 4} \\
\hline ALU & $P$ & $\mathrm{Z}$ & 54 & 0.002 & - & 5.8 & 0.18 & 0.4 & 0.2 & 0.4 & 0.012 & 0.96 & -0.9 & 0.004 & 2.1 \\
\hline ALU & $S$ & $\mathrm{~N}+\mathrm{E}$ & 54 & - & 0.035 & 3.5 & 0.59 & 0.38 & 0.46 & 1.5 & 0.042 & 0.29 & -0.58 & 0.048 & 2.45 \\
\hline SUDU & $P$ & $\mathrm{Z}$ & 6 & 0.003 & - & 5.2 & 0.16 & 0.45 & 0.08 & 0.3 & 0.008 & 1.07 & 1.03 & 0.002 & 2.1 \\
\hline SUDU & $S$ & $\mathrm{~N}+\mathrm{E}$ & 6 & 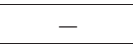 & 0.029 & 4.0 & 0.29 & 0.34 & 0.34 & 1.12 & 0.027 & 0.58 & -0.41 & 0.016 & 2.24 \\
\hline \multicolumn{7}{|c|}{$S$} & 0.26 & 0.39 & 0.22 & 0.67 & 0.018 & \begin{tabular}{|l|}
0.64 \\
\end{tabular} & -0.53 & 0.009 & 2.2 \\
\hline \multicolumn{7}{|c|}{$\delta S$} & 0.12 & 0.02 & 0.17 & 0.17 & 0.16 & 0.13 & - & 0.3 & 0.1 \\
\hline \multicolumn{16}{|c|}{ Землетрясег } \\
\hline ALU & $S$ & $\mathrm{~N}+\mathrm{E}$ & 161 & - & 0.18 & 3 & 8.17 & 0.45 & 4.01 & 13.4 & 0.43 & 1.3 & 0.7 & 5.46 & 3.21 \\
\hline SEV & $S$ & $\mathrm{~N}+\mathrm{E}$ & 213 & - & 0.02 & 5 & 1.69 & 0.27 & 3.83 & 12.8 & 0.25 & 6.3 & -4.4 & 1.08 & 2.76 \\
\hline $\mathrm{JDU}$ & $P$ & $\mathrm{Z}$ & 113 & 0.01 & 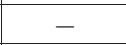 & 4.2 & 3.37 & 0.55 & 0.61 & 2.03 & 0.08 & 4.5 & -4.2 & 0.24 & 2.85 \\
\hline SUDU & $S$ & $\mathrm{~N}+\mathrm{E}$ & 113 & - & 0.097 & 2.3 & 4.39 & 0.58 & 0.97 & 3.23 & 0.14 & 2.4 & -1.94 & 0.71 & 0.03 \\
\hline \multicolumn{7}{|c|}{ 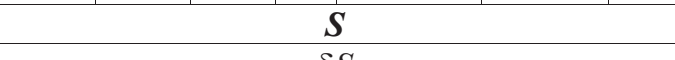 } & 3.78 & 0.44 & 1.74 & 5.79 & 0.19 & 3.1 & -2.23 & 1 & 3.0 \\
\hline \multicolumn{7}{|c|}{$\delta S$} & 0.14 & 0.08 & 0.21 & 0.21 & 0.16 & 0.15 & - & 0.28 & 0.15 \\
\hline \multirow{2}{*}{\multicolumn{16}{|c|}{\begin{tabular}{l|l|}
\multicolumn{3}{|c}{ Землетрясение (№ 3) } \\
\end{tabular}}} \\
\hline & & & & & & 1.6 & 10.5 & 0.88 & 0.67 & 2.2 & 0.14 & 2.85 & 2.5 & 1.2 & .28 \\
\hline
\end{tabular}
яние $\Delta, \kappa \mathcal{~}$, тип использованной волны $(P, S)$ и составляющая записи, где $(\mathrm{N}+\mathrm{E})$ означает полный вектор колебаний по $\mathrm{N}-\mathrm{S}$ и $\mathrm{E}-\mathrm{W}$ составляющим.

Tаблица 4. Спектральные и динамические параметры очагов землетрясений Крыма за 2015 г. 


\begin{tabular}{|c|c|c|c|c|c|c|c|c|c|c|c|c|c|c|c|}
\hline $\begin{array}{l}\text { Код } \\
\text { ст. }\end{array}$ & Волна & Сост & $\begin{array}{c}\Delta, \\
\kappa M\end{array}$ & $\begin{array}{c}\Omega_{0} \cdot 10^{-6} \\
{ }_{M} \cdot \mathcal{C}\end{array}$ & $\begin{array}{c}\Sigma \Omega_{0} \cdot 10^{-6} \\
{ }_{M} \cdot \mathcal{C}\end{array}$ & $\begin{array}{l}f_{0}, \\
\Gamma u\end{array}$ & $\begin{array}{c}M_{0} \cdot 10^{13} \\
H \cdot M\end{array}$ & $\begin{array}{l}r_{0}, \\
\kappa M\end{array}$ & $\begin{array}{c}\Delta \sigma \cdot 10^{5}, \\
П a\end{array}$ & $\varepsilon \cdot 10^{-6}$ & $\begin{array}{c}\bar{u} \cdot 10^{-2}, \\
\mathcal{M}\end{array}$ & $\begin{array}{c}\eta \sigma \cdot 10^{5} \\
П a\end{array}$ & $\begin{array}{c}\Delta \sigma_{\mathrm{r}} \cdot 10^{5} \\
\Pi a\end{array}$ & $\begin{array}{c}E_{\mathrm{u}} \cdot 10^{8}, \\
\text { Джжс }\end{array}$ & $M w$ \\
\hline 1 & 2 & 3 & 4 & 5 & 6 & 7 & 8 & 9 & 10 & 11 & 12 & 13 & 14 & 15 & 16 \\
\hline SEV & $P$ & $\mathrm{Z}$ & 323 & 0.008 & 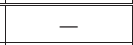 & 4.8 & 6.22 & 0.51 & 2.03 & 6.76 & 0.25 & 4.82 & -3.8 & 2.1 & 3.13 \\
\hline SEV & $\vec{c}$ & $\mathrm{~N}+\mathrm{E}$ & 323 & - & 0.065 & 2.6 & 9.65 & 0.54 & 2.62 & 8.73 & 0.35 & 3.11 & -1.8 & 4.2 & 3.26 \\
\hline UDC & $S$ & $\mathrm{~N}+\mathrm{E}$ & 212 & - & 0.26 & 2.2 & 21.5 & 0.61 & 4.16 & 1.39 & 0.61 & 1.4 & 0.7 & 14.9 & 3.49 \\
\hline \multicolumn{7}{|c|}{$S$} & 10.8 & 0.6 & 2 & 3.67 & 0.29 & 2.78 & -1.78 & 3.54 & 3.3 \\
\hline \multicolumn{7}{|c|}{$\delta S$} & 0.11 & 0.05 & 0.17 & 0.19 & 0.13 & 0.11 & - & 0.24 & 0.1 \\
\hline \multicolumn{16}{|c|}{ Землетрясение (№ 4) } \\
\hline ALU & $S$ & $\mathrm{~N}+\mathrm{E}$ & 107 & 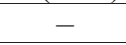 & 0.65 & 3 & 1.65 & 0.42 & 0.96 & 3.2 & 0.09 & 0.81 & -0.33 & 0.27 & 2.75 \\
\hline $\mathrm{JDU}$ & $P$ & $\mathrm{Z}$ & 73 & 0.009 & - & 5 & 1.2 & 0.45 & 0.59 & 1.96 & 0.06 & 0.12 & -0.83 & 0.12 & 2.66 \\
\hline JDU & $S$ & $\mathrm{~N}+\mathrm{E}$ & 73 & - & 0.78 & 2.8 & 1.3 & 0.40 & 0.89 & 2.98 & 0.09 & 1.03 & -0.59 & 0.19 & 2.68 \\
\hline \multirow{2}{*}{\multicolumn{7}{|c|}{$\delta S$}} & 1.37 & 0.42 & 0.8 & 2.65 & \begin{tabular}{|l|l|}
0.08 \\
\end{tabular} & 0.46 & -0.06 & 0.18 & 2.7 \\
\hline & & & & & & & 0.04 & 0.01 & 0.07 & 0.07 & 0.06 & 0.3 & 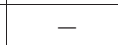 & 0.1 & 0.03 \\
\hline
\end{tabular}

\begin{tabular}{|c|c|c|c|c|c|c|c|c|c|c|c|c|c|c|}
\hline \multicolumn{15}{|c|}{ Землетрясение (№ 5) } \\
\hline SUDU & $P$ & $\mathrm{Z}$ & 84 & 0.003 & $\begin{array}{ccccc}- & \end{array}$ & 5.8 & 0.46 & 0.39 & 0.35 & 1.17 & 0.03 & 1.46 & -1.29 & \begin{tabular}{l|l}
0.03 & 2.38 \\
\end{tabular} \\
\hline SUDU & $S$ & $\mathrm{~N}+\mathrm{E}$ & 84 & - & 0.03 & 3.8 & 0.84 & 0.33 & 0.99 & 3.3 & 0.08 & 0.8 & -0.31 & \begin{tabular}{|l|l|}
0.14 & 2.55
\end{tabular} \\
\hline \multirow{2}{*}{\multicolumn{7}{|c|}{$\frac{S}{S}$}} & 0.62 & 0.36 & 0.59 & 2 & 0.05 & 1.1 & -0.81 & \begin{tabular}{|l|l|}
0.06 & 2.5 \\
\end{tabular} \\
\hline & & & & & & & 0.13 & 0.04 & 0.23 & 0.23 & 0.21 & 0.13 & - & 0.33 \\
\hline
\end{tabular}

Землетрясение (№ 6) 21 мая; $t_{0}=20^{\mathrm{h}} 52^{\mathrm{m}} 34.8^{\mathrm{s}} ; \varphi=43.38^{\circ}, \lambda=35.01^{\circ} ; h=7 \kappa \mu ; K_{\Pi}=9.0$

\begin{tabular}{|c|c|c|c|c|c|c|c|c|c|c|c|c|c|c|c|}
\hline \multirow{2}{*}{\multicolumn{2}{|c|}{$\Delta \mathrm{H}$}} & & & & & & & & & & & & & & \\
\hline ALU & & \begin{tabular}{l|l}
$Z$ & 1
\end{tabular} & 153 & 0.012 & - & 4 & 2.4 & 0.56 & 0.6 & 2.0 & 0.08 & 7.44 & -7.14 & 0.24 & \\
\hline $\mathrm{ALU}$ & $S$ & \begin{tabular}{ll|l}
$\mathrm{N}+\mathrm{E}$ & 1 \\
\end{tabular} & 153 & - & 0.3 & 2.4 & 10.9 & 0.53 & 3.25 & 10.8 & 0.42 & 1.64 & -0.09 & 5.92 & \\
\hline SEV & S & $+\mathrm{E}$ & 168 & - & 0.0 & 2.25 & 36 & 0.50 & 2 & 3.4 & 3 & 6.26 & & 9 & \\
\hline SIM & $S$ & $\mathrm{~N}+\mathrm{E}$ & 189 & $\begin{array}{lll}- & \\
-\end{array}$ & 0. & 1.9 & 10.1 & 0.59 & 2.17 & 7.24 & 1 & 1.77 & 7 & & \\
\hline DU & $P$ & $\mathrm{Z}$ & 168 & 0.04 & - & 3.1 & 7.44 & 0.6 & 1.5 & 5.0 & 2 & 2.4 & -1 & & \\
\hline DU & $S$ & 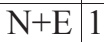 & 168 & - & 0.32 & 2 & 1.4 & 51 & 3.81 & 12.7 & 47 & 1.56 & 4 & 6 & \\
\hline & & & $S$ & & & & 6.32 & 0.54 & 1.7 & 5.69 & 0.23 & 2.82 & -1.97 & .8 & \\
\hline & & & $\delta S$ & & & & 0.12 & 0.01 & 0.13 & 0.13 & 0.12 & 0.12 & - & 0.25 & \\
\hline
\end{tabular}

Землетрясение (№ 7) 13 июня; $t_{0}=11^{\mathrm{h}} 54^{\mathrm{m}} 14.8^{\mathrm{s}} ; \varphi=46.47^{\circ}, \lambda=35.16^{\circ} ; h=11 \kappa$ к $; K_{\Pi}=10.8$

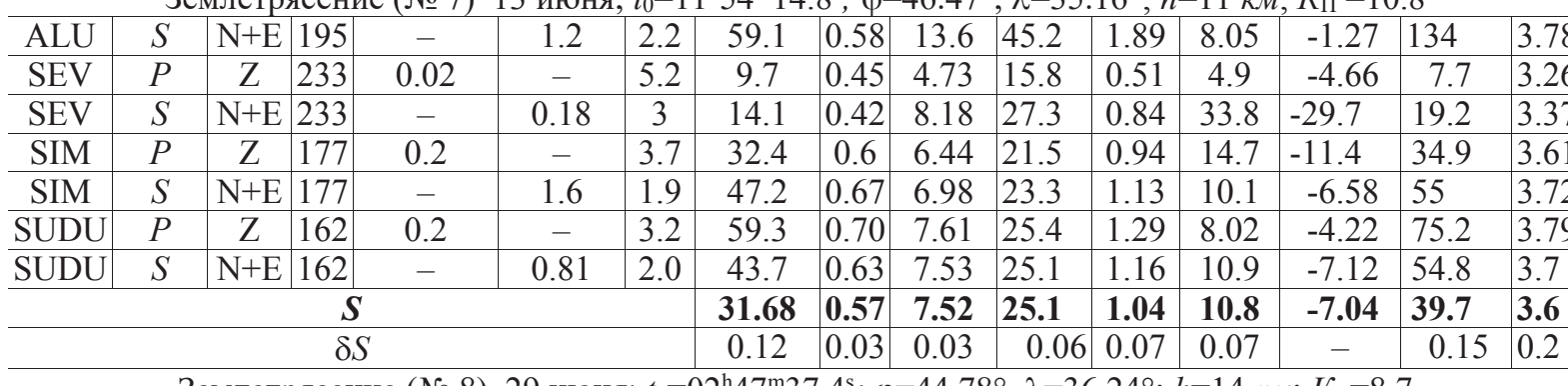

Землетрясение (№ 8) 29 июня; $t_{0}=02^{\mathrm{h}} 47^{\mathrm{m}} 37.4^{\mathrm{s}} ; \varphi=44.78^{\circ}, \lambda=36.24^{\circ} ; h=14 \kappa \mathrm{k} ; K_{\Pi}=8.7$

\begin{tabular}{|c|c|c|c|c|c|c|c|c|c|c|c|c|c|c|c|}
\hline ALU & & & & & & & & & & 25 & 063 & 10 & 200 & 106 & \\
\hline SEV & $S$ & $\mathrm{~N}+\mathrm{E}$ & 204 & - & 0.018 & 3.2 & 1.23 & 0.40 & 0.87 & 2.9 & 0.08 & 8.7 & -8.24 & 0.18 & \\
\hline SUDU & $P$ & Z & 95 & 0.01 & - & 4.6 & 1.81 & 0.49 & 0.69 & 2.31 & 0.08 & 5.87 & -5.52 & 0.21 & \\
\hline SUDU & $S$ & $\mathrm{~N}+\mathrm{E}$ & 95 & - & 0.12 & 2.9 & 3.96 & 0.44 & 0.21 & 6.94 & 0.22 & 2.69 & -1.65 & 1.57 & \\
\hline \multicolumn{7}{|c|}{$S$} & 3.10 & 0.44 & 0.94 & 5.56 & 0.17 & 3.42 & -2.95 & 0.89 & \\
\hline \multicolumn{7}{|c|}{$\delta S$} & 0.21 & 0.02 & 0.3 & 0.22 & 0.21 & 0.21 & - & 0.4 & 0.2 \\
\hline
\end{tabular}

Землетрясение (№ 9) 5 июля; $t_{0}=13^{\mathrm{h}} 23^{\mathrm{m}} 34.1^{\mathrm{s}} ; \varphi=45.74^{\circ}, \lambda=36.69^{\circ} ; h=18 \mathrm{\kappa m} ; K_{\Pi}=9.9$

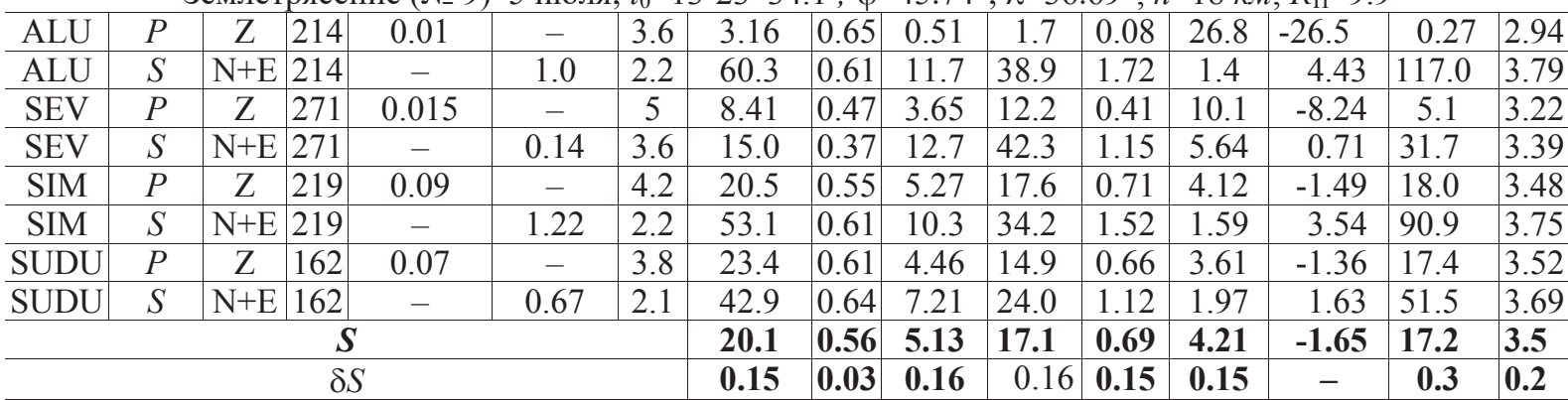

Землетрясение (№ 10) 16 августа; $t_{0}=22^{\mathrm{h}} 38^{\mathrm{m}} 0.2^{\mathrm{s}} ; \varphi=44.56^{\circ}, \lambda=37.39^{\circ}, h=7 \mathrm{kм} ; K_{\Pi}=10.8$

\begin{tabular}{c|c|c|c|c|c|c|c|c|c|c|c|c|c|c|c}
\hline ALU & $P$ & Z & 237 & 0.015 & - & 2.9 & 35.9 & 0.8 & 3.11 & 10.4 & 0.6 & 13.3 & -11.7 & 18.6 & 3.64 \\
\hline ALU & $S$ & N+E & 237 & - & 1.0 & 1.7 & 64.4 & 0.74 & 6.81 & 22.7 & 1.23 & 7.39 & -3.98 & 73.1 & 3.81 \\
\hline SEV & $S$ & N+E & 294 & - & 0.22 & 1.8 & 49.2 & 0.70 & 6.19 & 20.6 & 1.06 & 9.66 & -6.56 & 50.8 & 3.73 \\
\hline SIM & $S$ & N+E & 262 & - & 1.56 & 1.55 & 104 & 0.82 & 8.32 & 27.7 & 1.65 & 4.58 & -0.58 & 144 & 3.95
\end{tabular}




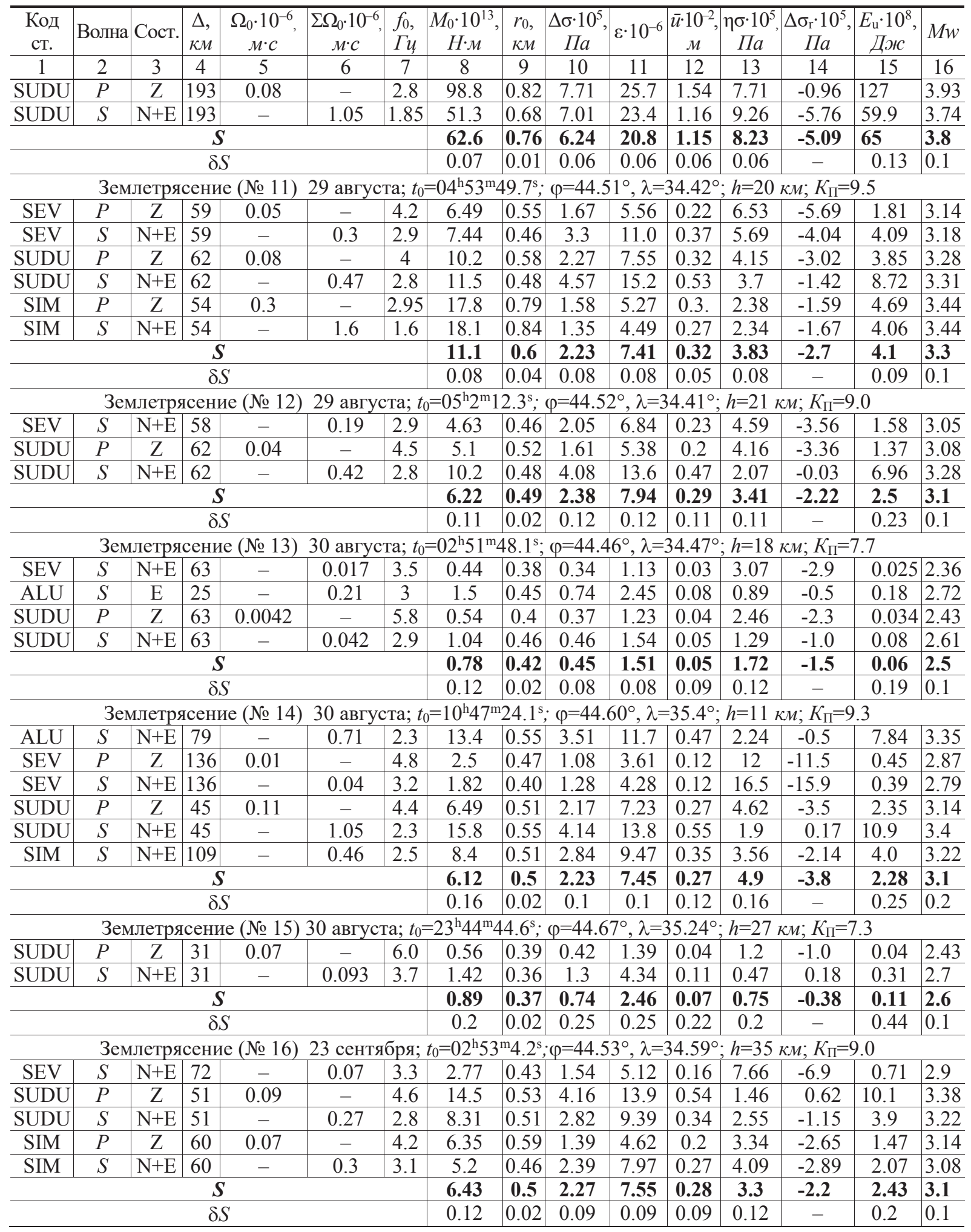

Примечание: $\Sigma \Omega_{0} \cdot 10^{-6},{ }^{\cdot} \cdot c-$ спектральная плотность по полному вектору колебаний поперечной волны.

Обсуждение результатов. Наилучшая сходимость станционных определений динамических параметров очагов землетрясений Крыма (табл. 4) получена для радиуса круговой дислокации, размеры которой в явном виде не зависят от направленности излучения энергии из очага и условий среды под станцией регистрации. Степень рассеяния индивидуальных определений $r_{0}$ для большинства изученных землетрясений находилась в диапазоне $\delta r_{0}=0.01 \div 0.02$. Стандартные отклонения $\delta S$ по другим параметрам для большинства землетрясений $\delta S<0.2$. Наименьшие отклонения $\delta S<0.1$ получены для землетрясения 16 августа с $K_{\Pi}=10.8$ (№ 10), при оценке сейсмичес- 
кого момента которого введена реальная поправка за направленность излучения из очага на станции регистрации (табл. 3). Уверенно определены средние значения моментных магнитуд $M w$ с погрешностью не выше \pm 0.2 и с преобладанием $\delta M w= \pm 0.1$. Для магнитудных оценок это достаточно высокая точность.

Наибольшие значения динамических параметров $\left(M_{0}, r_{0}, \Delta \sigma, \varepsilon, \eta \sigma, u, E_{\mathrm{U}}\right.$ и $\left.M w\right)$ получены для двух наиболее сильных землетрясений региона, 13 июня (№ 7) и 16 августа (№ 10) с $K_{\Pi}=10.8$, произошедших в Азово-Кубанском и Керченско-Анапском районах на глубинах, соответственно, $h=11 \kappa м$ и $h=7 \kappa м$. В целом, с ростом энергетического уровня землетрясений количественные значения динамических параметров очагов увеличивались в пределах разброса измеряемых величин. Радиационное трение $\Delta \sigma_{r}$ для всех исследованных землетрясений имело отрицательное значение, указывая на сложное скольжение разрыва в очаге за счет неравномерного распределения прочностных свойств глубинной среды в очаговых зонах [11]. Для всего диапазона энергетического уровня изученных землетрясений средняя величина сброшенных напряжений не превысила

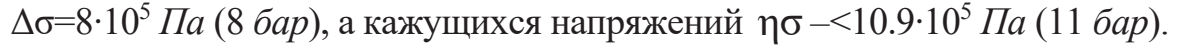

Анализ станционных определений по данным за 2015 г. показал, что значения сейсмических моментов $M_{0}$ и, соответственно, моментной магнитуды $M w$, восстановленные по записям станции «Севастополь», как по продольным, так и поперечным волнам во всех случаях получились существенно ниже, чем по записям станций «Судак» и «Симферополь». В дальнейшем предполагается на статистически значимом материале установить, являются ли эти станционные отклонения систематическими для всех очаговых зон и глубин очагов. По результатам будут либо введены соответствующие поправки, либо установлено, что имеются технические ошибки в расчетах амплитудно-частотных характеристик регистрирующей цифровой аппаратуры на станции.

Сравнение полученных в 2015 г. динамических параметров очагов с их средними долговременными величинами [14], как и в предыдущие годы [15-17], проведено только для сейсмического момента $M_{0}$ и радиуса круговой дислокации $r_{0}$ (рис. 5). Эти параметры определяются непосредственно по спектрам записей сейсмических колебаний на станциях регистрации, а остальные параметры вычисляются по их значениям. Для сравнения использованы зависимости $M_{0}\left(K_{\Pi}\right)$ и $r_{0}\left(K_{\Pi}\right)$ из [14]:

$$
\begin{gathered}
\lg M_{0}=0.645( \pm 0.027) \cdot K_{\Pi}+15.142( \pm 0.271), \rho=0.99, \\
\lg r_{0}=0.112( \pm 0.011) \cdot K_{\Pi}-1.293( \pm 0.107), \rho=0.93,
\end{gathered}
$$

где $\rho$ - коэффициент корреляции.

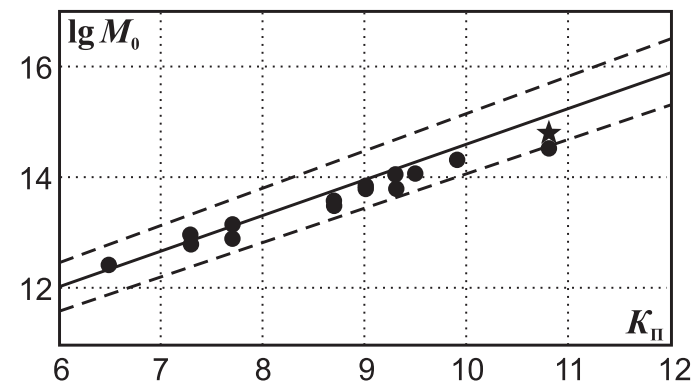

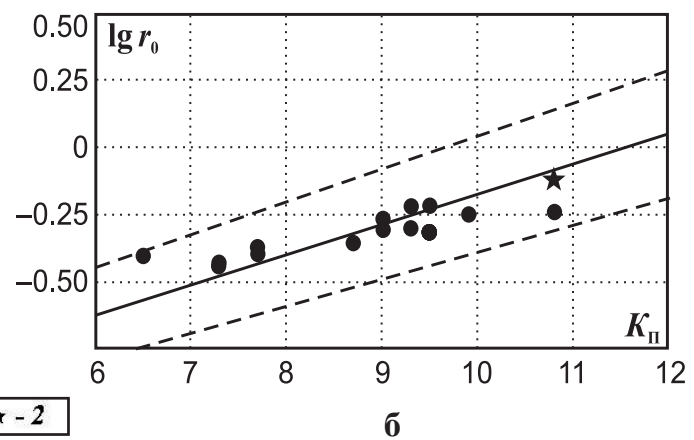

Puc. 5. Сравнение динамических параметров очагов землетрясений за 2014 г.: сейсмического момента (а) и радиуса круговой дислокации $r_{0}(б)$ с долговременными зависимостями $M_{0}\left(K_{\Pi}\right)$ и $r_{0}\left(K_{\Pi}\right)$ из $[14]$

1 - экспериментальные значения за 2015 г.; 2 - значения для землетрясения с известным механизмом очага; пунктиром обозначены пределы погрешностей.

Из рисунка 5 наглядно видно, что для большинства землетрясений 2015 г. средние значения $M_{0}$ и $r_{0}$ находятся в пределах доверительных областей долговременных зависимостей $M_{0}\left(K_{\Pi}\right)$, $r_{0}\left(K_{\Pi}\right)$. При этом значения $r_{0}$ были равномерно распределены относительно регрессии $r_{0}\left(K_{\Pi}\right)$, а $M_{0}$ в основном располагались ниже средней зависимости $M_{0}\left(K_{\Pi}\right)$. Наибольшее отличие $M_{0}$ от долговременных параметров по зависимости $M_{0}\left(K_{\Pi}\right)$ получено для землетрясения 13 июня 
(№ 7) с $K_{\Pi}=10.8$, произошедшего на северном побережье Азовского моря. Это может быть связано как с участием в осреднении $M_{0}$ данных по станции «Севастополь», дающей заниженные значения $M_{0}$, так и с возможными ошибками в определении глубины очага в краевой зоне региона $(h=11 \kappa M)$, влияющими на выбор скоростных моделей среды для расчета $M_{0}$. Как следует из формулы (1), точность оценок $M_{0}$ существенно зависит от корректности задания условий модели среды в районе очага и пути распространения сейсмических волн. Так, отнесение гипоцентра к верхней части земной коры или нижней (при ошибке $\delta h=5-10 \kappa м$ ) может привести к различиям в сейсмическом моменте почти в 2 раза. Кроме того, невозможно точно учесть не только многообразие физических свойств среды на пути распространения сейсмических колебаний и в верхней толще пород под станциями регистрации, но также направленности излучения без знания механизма очагов слабых землетрясений.

Заключение. Для надежных оценок очаговых параметров землетрясений Крыма за 2015 г. использованы не только записи нескольких станций, но и разных типов волн. В осреднении очаговых параметров $(\boldsymbol{S})$ участвовало от двух до восьми станционных определений, что обеспечило в основном малую величину стандартного отклонения $\delta S$, показателя степени рассеяния индивидуальных оценок. В этом отношении дополнительно полученные очаговые параметры 16 землетрясений 2015 г. можно отнести к категории надежных для пополнения базы исходных данных, необходимых для построения геодинамических моделей региона и использования в прикладных задачах инженерной сейсмологии.

\section{Л и т е р а т у р а}

1. Козиненко Н.М., Свидлова В.А., Сыкчина 3.Н. (отв. сост.). Каталог землетрясений Крыма за 2015 г. // Землетрясения Северной Евразии. - 2021. - Вып. 24 (2015 г.). - [Электронное приложение]. - URL: http://www.ceme.gsras.ru/zse/app-24.html

2. Пустовитенко Б.Г., Кульчицкий В.Е. Об энергетической оценке землетрясений Крымско-Черноморского региона // Магнитуда и энергетическая классификация землетрясений. - М.: ИФЗ АН СССР, 1974. - T. 2. - C. 113-125.

3. International Seismological Centre. (2021). On-line Bulletin. https://doi.org/10.31905/D808B830

4. Пустовитенко Б.Г. (отв. сост.) Каталог механизмов очагов землетрясений Крымско-Черноморского региона за 2015 г. // Землетрясения Северной Евразии. - 2021. - Вып. 24 (2015 г.). - [Электронное приложение]. - URL: http://www.ceme.gsras.ru/zse/app-24.html

5. Балакина Л.А., Введенская А.В., Голубева Н.В., Мишарина Л.А., Широкова Е.И. Поле упругих напряжений Земли и механизм очагов землетрясений. - Москва: Наука, 1972. - 198 с.

6. Kennet B.L.N. Seismological Tables: ak135 // Research School of earth Sciences Australian national University. - Australia, Canberra, ACT0200, 2005. -80 p.

7. Кульчицкий В.Е., Сафонова Г.П., Свидлова В.А. Годографы сейсмических волн Крымско-Черноморских землетрясений // Сейсмологический бюллетень Западной территориальной зоны ЕССН СССР (Крым-Карпаты) за 1983 г.- Киев: Наукова думка, 1986. - С. 94-103.

8. Пустовитенко Б.Г., Пантелеева Т.А. Спектральные и очаговые параметры землетрясений Крыма. Киев: Наукова думка, 1990. - 251 с.

9. Brune I.V. Tectonic stress and the spectra of seismic shear waves from earthquakes // Journal of Geophysical Research. - 1970. - V. 75, N 26. - P. 4997-5009.

10. Аптекман Ж.Я., Белавина Ю.Ф., Захарова А.И., Зобин В.М., Коган С.Я., Корчагина О.А., Москвина А.Г., Поликарпова Л.А., Чепкунас Л.С. Спектры $P$-волн в задаче определения динамических параметров очагов землетрясений. Переход от станционного спектра к очаговому и расчет динамических параметров очага // Вулканология и сейсмология. - 1989. - № 2. - С. 66-79.

11. Костров Б.В. Механика очага тектонического землетрясения. - М.: Наука, 1975. -179 с.

12. Кейлис-Борок В.И. Исследование источников, приближенно эквивалентных очагам землетрясений // Труды Геофизического Института АН СССР. - 1959. - № 9 (136). - С. $20-42$.

13. Hanks T.C., Kanamori H.A. Moment magnitude scale // Journal of Geophysical Research. - 1979. - V. 84, N 35. - P. 2348-2350.

14. Пустовитенко Б.Г., Пустовитенко А.А., Капитанова С.А., Поречнова Е.И. Пространственные особенности очаговых параметров землетрясений Крыма. Сейсмичность Северной Евразии. - Обнинск: ГС РАH, 2008. - С. 238-242. 
15. Пустовитенко Б.Г., Калинюк И.В., Пустовитенко А.А. Очаговые параметры землетрясений КрымскоЧерноморского региона // Землетрясения Северной Евразии. - Вып. 21 (2012 г.). - Обнинск: ФИЦ ЕГС РАН, 2018. - С. 286-293.

16. Пустовитенко Б.Г., Калинюк И.В. Очаговые параметры землетрясений Крымско-Черноморского региона // Землетрясения Северной Евразии - Вып. 22 (2013 г.). - Обнинск: ФИЦ ЕГС РАН, 2019. C. 299- 310 .

17. Пустовитенко Б.Г., Эреджепов Э.Э. Спектральные и динамические параметры очагов землетрясений Крыма 2014 года // Ученые записки Таврического национального университета им. В.И. Вернадского; серия «География» - 2014. - Т. 27 (66), № 4. - С. 70-86.

\title{
SOURCE PARAMETERS of CRIMEAN-BLACK SEA EARTHQUAKES in 2015
}

\author{
B.G. Pustovitenk ${ }^{1}$, E.E. Eredzhepov ${ }^{1,2}$
}

\author{
${ }^{1}$ State Autonomous Institution "Crimean Republican Center for Seismic and Landslide Hazard Assessment, \\ Technical Inspection of Construction Facilities” \\ ${ }^{2}$ Institute of Seismology and Geodynamics, V.I. Vernadsky Crimean Federal University, \\ Simferopol, Republic of Crimea, RussiaE-mail: bpustovitenko@mail.ru
}

\begin{abstract}
The spectral and dynamic source parameters $\left(M_{0}, r_{0}, \Delta \sigma, \varepsilon, \eta \sigma, \Delta, u, E \mathrm{u}\right.$ and $\left.M w\right)$ of 16 Crimean earthquakes with $K_{\Pi}=6.5-10.8$, restored by amplitude spectra of compression and shear seismic waves recorded by digital regional seismic stations are analyzed. Approximation of the spectra and source parameters calculation is performed in the framework of the Brune dislocation model. The highest values of dynamic parameters $\left(M_{0}, r_{0}\right.$, $\Delta \sigma, \varepsilon, \eta \sigma, u, E_{\mathrm{U}}$ и $\left.M w\right)$ are obtained for the earthquakes on June 13 and August 16 with $h=11 \mathrm{~km}, \mathrm{~h}=7 \mathrm{~km}$ respectively and $K_{\Pi}=10.8$, which occurred in the Azov-Kuban and Kerch-Anapa areas. The radiation friction $\Delta \sigma_{r}$ for all earthquakes had a negative value, pointing to a complex slide of the rupture in the source. Within the whole energy range, the average value of the released stress did not exceed $\Delta \sigma=8 \cdot 10^{5} \mathrm{PA}(8 \mathrm{bar})$ and apparent stress $\eta \sigma<11 \cdot 10^{5} \mathrm{PA}$ (11 bar). For most 2015 earthquakes, the average $M_{0}$ и $r_{0}$ values were within the confidence intervals of long-term dependencies $M_{0}\left(K_{\Pi}\right), r_{0}\left(K_{\Pi}\right)$. The values of $r_{0}$ were evenly distributed concerning the regression $r_{0}\left(K_{\Pi}\right)$ and $M_{0}$ is mostly located below the average according to $M_{0}\left(K_{\Pi}\right)$. The maximum deviations of $M_{0}$ from the long-term $M_{0}\left(K_{\Pi}\right)$ dependence were obtained for the most strong earthquakes on June 13 and August 16 with $K_{\Pi}=10.8$. These deviations can be associated with participation in average $M_{0}$ of the "Sevastopol" station data which give low values of $M_{0}$ and possible errors in determining the focal depths influencing the choice of environment velocity models to calculate $M_{0}$. For the most strong earthquake of August 16 with $M w=3.8$, which occurred in the Kerch-Anapa region, a solution of focal mechanism was obtained. The earthquake occurred under the action of horizontal latitudinal tensile forces. The type of movement in the source is an oblique normal fault. Both nodal planes have nearmeridional $\left(S T K_{\mathrm{NP} 1}=167^{\circ}\right)$ and near-diagonal $\left(S T K_{\mathrm{NP} 2}=336^{\circ}\right)$ strike.
\end{abstract}

Keywords: focal mechanism, amplitude spectrum, Brune model, spectral density, corner frequency, seismic moment, dislocation radius, apparent stress drop, radiation friction.

DOI: $10.35540 / 1818-6254.2021 .24 .22$

For citation: Pustovitenko, B.G., \& Eredzhepov E.E. (2021). [Source Parameters of Crimean-Black Sea Earthquakes in 2015]. Zemletriaseniia Severnoi Evrazii [Earthquakes in Northern Eurasia], 24(2015), 226-236. (In Russ.). doi: 10.35540/1818-6254.2021.24.22

\section{$R$ e f e r e n e s}

1. Kozinenko, N.M., Svidlova, V.A., \& Sykchina, Z.N. (2021). [Catalog of earthquakes in the Crimean Black Sea region for 2015]. Zemletriaseniia Severnoi Evrazii [Earthquakes in Northern Eurasia], 24(2015). Electronic supplement. Retrieved from http://www.ceme.gsras.ru/zse/app-24.html (In Russ).

2. Pustovitenko, B.G., \& Kul'chickij, V.E. (1974). [On the energy assessment of earthquakes of Crimean Black Sea region. Earthquake magnitude and energy classification]. In Magnituda i energeticheskaya klassifikaciya zemletryasenij [Magnitude and energy classification of earthquakes] (pp. 113-125). Moscow, Russia: IFZ RAS Publ. (In Russ.).

3. International Seismological Centre. (2021). On-line Bulletin. Retrieved from https://doi.org/10.31905/ D808B830

4. Pustovitenko, B.G. (2021). [Catalog of earthquake focal mechanisms in the Crimean Black Sea region for 2015]. Zemletriaseniia Severnoi Evrazii [Earthquakes in Northern Eurasia], 24(2015). Electronic supplement. Retrieved from http://www.ceme.gsras.ru/zse/app-24.html (In Russ.). 
5. Balakina, L.A., Vvedenskaya, A.V., Golubeva, N.V., Misharina, L.A., \& Shirokova, E.I. (1972). Pole uprugikh napryazheniy zemli i mekhanizm ochagov zemletryaseniy. [Field of elastic stresses of the Earth and the mechanism of earthquake foci]. Moscow, Russia: Nauka Publ., 198 p. (In Russ.).

6. Kennet B.L.N. (2005). Seismological Tables: ak135. Research School of earth Sciences Australian National University. Australia, Canberra, ACT0200.

7. Kul'chickij, V.E., Safonova, G.P., \& Svidlova, V.A. (1986). [Hodographs of seismic waves of the CrimeanBlack sea earthquakes]. In Seismologicheskii biulleten' Zapadnoi territorial'noi zony ESSN SSSR (KrymKarpaty) za 1983 g. [Seismological Bulletin of the Western Territorial Zone of the ESSN of the USSR (Crimea-Carpathians) for 1983] (pp. 94-103). Kyiv, Ukraine: Naukova Dumka Publ. (In Russ.).

8. Pustovitenko, B.G., \& Panteleeva, T.A. (1990). Spektral'nye i ochagovye parametry zemletryasenij Kryma. [Spectral and focal parameters of earthquakes of the Crimea]. Kiev, Ukraine: Naukova Dumka Publ., 251 p. (In Russ.).

9. Brune, J.N. (1970). Tectonic stress and the spectra of seismic shear waves from earthquakes. Journal of geophysical research, 75(26), 4997-5009.

10. Aptekman, J.Ya., Belavina, Yu.F., Zakharova, A.I., Zobin, V.M., Kogan, S.Ya., Korchagina, O.A., Moskvina, A.G., Polikarpova, L.A., \& Chepkunas, L.S. (1989). [Spectra of P-waves in the problem of determining the dynamic parameters of earthquake sources. The transition from station to focal range and the calculation of dynamic source parameters]. Vulkanologiya $i$ sejsmologiya Journal of [Volcanology and seismology], 2, 66-79. (In Russ.).

11. Kostrov, B.V. (1975). Mekhanika tektonicheskogo ochaga zemletryaseniya [Mechanics of the tectonic earthquake focus]. Moscow, Russia: Nauka Publ., 179 p. (In Russ.).

12. Keilis-Borok, V.I. (1959). [Study of the sources, approximately equivalent to the foci of earthquakes]. Tr. Geofizicheskogo Instituta AN SSSR [Proc. Geophysical Institute of Academy of Sciences of the USSR], 9(136), 20-42. (In Russ.).

13. Hanks, T.C., \& Kanamori, H.A. (1979). Moment magnitude scale. Journal of Geophysical Research, 84(35), 2348-2350.

14. Pustovitenko, B.G., Pustovitenko, A.A., Kapitanova, S.A., \& Porechnova, E.I. (2008). [Spatial features of focal parameters of earthquakes in the Crimea]. In Materialy mezhdunarodnoi konferentsii. Seismichnost' Severnoi Evrazii [Proceedings of the international conference. Seismicity in Northern Eurasia] (pp. 238242). Obninsk, Russia: GS RAS Publ. (In Russ.).

15. Pustovitenko, B.G., Kalinyuk, I.V., \& Pustovitenko, A.A. (2018). [Focal parameters of earthquakes of the Crimea in 2012]. Zemletriaseniia Severnoi Evrazii [Earthquakes in Northern Eurasia], 21(2012), $286-293$. (In Russ.).

16. Pustovitenko, B.G., \& Kalinyuk, I.V. (2019). [Focal parameters of earthquakes of the Crimean-Black Sea region]. Zemletriaseniia Severnoi Evrazii [Earthquakes in Northern Eurasia], 22(2013), 299-310. (In Russ.).

17. Pustovitenko, B.G., \& Eredzhepov, E.E. (2014). [Spectral and dynamic parameters of the centers of the earthquakes of Crimea in 2014]. In Uchenye zapiski Tavricheskogo natsional'nogo universiteta im. V.I. Vernadskogo; seriia «Geografiia» [Scientific notes of the Tavrichesky National University named after V.I. Vernadsky; series "Geography"], 27(4), 70-86. 